\title{
eApples: A Case Study in Using eXtension to Increase Access to Research-based Information
}

\author{
Emily E. Hoover ${ }^{1,15}$, Richard P. Marini ${ }^{2}$, Emily Tepe ${ }^{1}$, \\ Wesley R. Autio ${ }^{3}$, Alan R. Biggs ${ }^{4}$, Jon M. Clements ${ }^{5}$, \\ Robert M. Crassweller ${ }^{2}$, Daniel D. Foster ${ }^{6}$, Melanie J. Foster ${ }^{7}$, \\ Peter M. Hirst ${ }^{8}$, Diane Doud Miller ${ }^{9}$, Michael L. Parker ${ }^{10}$, \\ Gregory M. Peck ${ }^{11}$, Jozsef Racsko ${ }^{12}$, Terence L. Robinson ${ }^{13}$, \\ and Michele R. Warmund ${ }^{14}$
}

ADDITIONAL INDEX wORDs. apple rootstocks, apple cultivars, apple varieties, Malus $\times$ domestica

SUMMARY. Researchers have collected a considerable amount of data relating to apple (Malus $\times$ domestica) cultivars and rootstocks over the past 30 years, but much of this information is not easily accessible. The long-term goal of our working group is to increase access to this information using online technology available through eXtension. In eXtension, researchers and extension personnel are developing a community of practice $(\mathrm{CoP})$ to increase the quality and amount of online information for individuals interested in our work [referred to as a community of interest (CoI)]. For this project, our CoI is broadly defined as commercial apple producers, nursery professionals, county extension educators, Extension Master Gardeners, home gardeners, and consumers. Our CoP is developing diverse educational tools, with the goals of increasing productivity, profitability, and sustainability for commercial apple production. Additionally, we will provide other members of our CoI access to research-based, reliable information on the culture of apples. We chose to begin our focus on cultivars and rootstocks adapted to the eastern United States and will add other U.S. regions as our resources and interest in our project grows.

A pple producers throughout the United States, from large commercial growers to home gardeners with a few trees, have limited access to research-based information describing apple cultivars and rootstocks for their region. Most research information has been confined to scientific journals, mostly inaccessible to the public. Reliable information on the Internet can be hard to find because of the sheer volume of websites returned in a typical web search. For example, a search for "apple rootstocks" on the web search engine Google (Mountain View, CA) returns about 200,000 results. University and state extension services have worked hard to present reliable research-based rootstock and cultivar information, but most of their sites are static, dependent on an ever-smaller number of individuals with the knowledge base. Our project will add information to what is offered on university and state extension websites by providing easily accessible, scientific, unbiased, apple rootstock and cultivar information through a growing national resource, eXtension web portal (eXtension, 2012).

In 2001, a decision was made at the national level to transform the way Cooperative Extension delivers information through technology. After a few years of developing the administrative structure for the system the eXtension prototype was introduced in 2005. In 2007, the full system was launched to provide access to the land-grant university system with rules of operation, governing committee, staff, and long-term implementation plan. Additionally, U.S. Department of Agriculture (USDA), National Institute for Food and Agriculture (NIFA) launched a national grant program entitled Specialty Crops Research Initiative providing grant funding, in part, to assist in developing our type of eXtension project. Our CoP was funded for a 3-year period beginning Fall 2010.

Some aspects of growing apples are applicable to any size operation in any region of the United States. However, two critical aspects of production vary greatly from region to region and contribute to the challenge of growing high quality fruitcultivar and rootstock. Over 2500 apple cultivars are grown in the United States (U.S. Apple Association, 2012). Each of these cultivars is best suited to a certain region, depending on multiple environmental conditions including climate, soil, and pest complex. Some cultivars, such as Gala and Empire, survive and produce fruit from the lower mountains of North Carolina to the Champlain Valley in Vermont (USDA hardiness zones $4 \mathrm{~b}$ to 7a); other cultivars, such as McIntosh and Honeycrisp, survive in hardiness zone $3 \mathrm{~b}$, but produce poorer quality fruit in regions warmer than zone 6a; and long-season cultivars, such as Granny Smith and Pink Lady ${ }^{\mathrm{TM}}$, may not mature properly when grown in regions colder than zone 7a (Crassweller, 2008; Marini, 1996).

Rootstock survival and performance also vary with soil type and climate. For example, the dwarfing rootstock 'Budagovsky 9' (B.9) produces trees of similar size in Arkansas, British Columbia, Kentucky, and Illinois, whereas the trees on 'M.26' (M.26EMLA) were twice as large in Kentucky and Illinois as those in Arkansas and British Columbia (Autio et al., 2008). Therefore, tree spacing recommendations for a given rootstock must be modified based on the region. The semidwarf rootstock 'M.7' (M.7) performs quite well with 'McIntosh' and 'Empire' in the northeastern United States, but when grafted to cultivars grown in the mid-Atlantic region, such as Stayman, Gala, and Granny Smith, the trees need a support structure such as a trellis or they fall over (Marini, 1996).

Fruit losses to disease vary from region to region, so pest management programs must be modified, both for cultivars across regions and also for different cultivars within a region. Several apple breeding programs have introduced new cultivars that are resistant to several diseases. Since most of the breeding programs are in the northern United States, they are selecting for resistance to apple scab (Venturia inaequalis), powdery mildew (Podosphaera leucotricha), cedar-apple rust (Gymnosporangium juniperi-virginianae), 
and fire blight (Erwina amylovora). Unfortunately, none are selecting for resistance to summer rots such as black rot (Botryosphaeria obtusa), white rot (B. dothidea), and bitter rot (Glomerella cingulata), which can be severe in warmer, humid climates. In Virginia, the apple scab-resistant cultivars Freedom and Redfree were quite susceptible to bitter rot (Barden and Marini, 1998). In West Virginia, there was no relationship between relative susceptibility to either quince rust (Gymnosporangium clavipes) or cedarapple rust and apple scab, but the apple scab-resistant cultivars Sundance, Enterprise, and selections from the Cornell University breeding program (NY 65707-19, NY 754141 , NY 79507-72, and NY 79507-49) were among the most resistant to cedar-apple rust. This resistance is an important attribute for early season

\footnotetext{
This paper was part of the workshop "The Growing Involvement of Horticulture in eXtension: Updates and Opportunities" held 27 Sept. 2011 at the ASHS Conference, Waikoloa, HI, and sponsored by the eXtension (EEXT) Working Group.

Our research group would like to thank USDA-SCRI
} for funding this project in part

${ }^{1}$ Department of Horticultural Science, University of Minnesota, 305 Alderman Hall, 1970 Folwell Avenue, St. Paul, MN 55108

${ }^{2}$ Department of Horticulture, The Pennsylvania State University, 119 Tyson Building, University Park, PA 16802

${ }^{3}$ Department of Plant Soil and Insect Sciences, University of Massachusetts, 205 Bowditch Hall, 201 Natural Resources Rd., Amherst, MA 01003

${ }^{4}$ Plant and Soil Science, West Virginia University, Kearneysville TFREC, P.O. Box 609, Kearneysville, WV 25430

${ }^{5}$ University of Massachusetts, 393 Sabin Street, Belchertown, MA 01007

${ }^{6}$ Agricultural and Extension Education, The Pennsylvania State University, 0211 Ferguson Building, University Park, PA 16802

${ }^{7}$ The Pennsylvania State University, 106 Agricultural Administration Building, University Park, PA 16802

${ }^{8}$ Department of Horticulture and Landscape Architecture, Purdue University, 625 Agriculture Mall Drive, West Lafayette, IN 47907

${ }^{9}$ Horticulture and Crop Science, The Ohio State University, 203A Williams OARDC, Wooster, OH 44691

${ }^{10}$ Horticultural Science, North Carolina State University, Kilgore Hall 150, Box 7609, Raleigh, NC 27695

${ }^{11}$ Department of Horticulture, Virginia Polytechnic Institute and State University, 595 Laurel Grove Road, Winchester, VA 22602

${ }^{12}$ Horticulture and Crop Science, The Ohio State University, 203A Williams, OARDC, Wooster, $\mathrm{OH}$ 44691

${ }^{13}$ NYS Agricultural Experiment Station, Cornell University, Geneva, NY 14456

${ }^{14}$ Division of Plant Sciences, University of Missouri, 1-59 Agriculture Building, Columbia, MO 65211

${ }^{15}$ Corresponding author. E-mail: hoove001@umn.edu. disease management in areas where cedar-apple rust reduces yield and fruit quality, and particularly so if the orchard is being managed to organic standards. 'Sundance' was also the least susceptible to quince rust. By contrast, the scab-resistant cultivars GoldRush, Pristine, Scarlet O'Hara, Princess, Crimson Crisp, and CQR10T17 were highly susceptible to cedar-apple rust and would require early season fungicide applications for rust management in high-inoculum areas in spite of their resistance to apple scab (Biggs et al., 2009a).

Most of the dwarfing rootstocks are very susceptible to the bacterial disease fire blight and are not recommended in regions with a history of fire blight, such as Ohio, but the rootstock B.9 and the new Geneva ${ }^{\circledR}$ rootstocks appear much more tolerant to fire blight (Miller and Myers, 2006). By selecting cultivar-rootstock combinations with known tolerance to pests in their region, growers will be able to produce quality apples with minimal pesticide use and increased profitability.

In the late 1800s and early 1900s, most land-grant universities had apple breeding programs to develop new cultivars well suited to their local conditions (Magness, 1937). By the middle of the 20th century only a few breeding programs remained, but most universities continued to evaluate cultivars and rootstocks. In the 1960s, the first apple rootstock breeding program in the United States was established at Geneva, NY, to develop rootstocks for the northeastern United States (Cummins and Aldwinckle, 1974). In 1998, the USDA formed a partnership with Cornell University and the program was expanded to include a national emphasis.

By the 1970s, a substantial volume of research information existed about cultivars and rootstocks from around the country, but many reports from these trials were contradictory because of differences in cultivar-rootstock combination, experimental design, tree management, and type of data collected. In the mid-1970s, the North Central Regional Project NC-140 (NC-140) was established to uniformly evaluate apple rootstocks throughout the United States. The project quickly grew to include cooperators from 23 states, five Canadian provinces, and one Mexican state
[National Information Management and Support System (NIMSS), 2012a]. The project was further expanded to include other deciduous tree fruit species. Rootstocks obtained from breeding programs in Europe, Asia, Canada, and the United States were used to propagate trees at a single nursery, and uniform trials were established at many locations in an attempt to hold all variables constant except soil and climate. Because these trials rapidly exposed rootstocks to a wide range of conditions, the time to adequately test new rootstocks was reduced from more than 40 years to just 10 years. Results from 15 NC- 140 apple rootstock trials have been summarized in more than 30 refereed journal articles, as well as numerous newsletters and presentations at grower meetings. Results from NC-140 trials now form the basis for all rootstock recommendations in North America, and information about the project and literature citations are available on the NC-140 website (NC-140 Regional Research Project, 2012).

In the 1980s, many new apple cultivars were released from breeding programs in North America, the southern hemisphere, and Europe. To quickly evaluate these new cultivars, a regional project, NE-183 (renamed NECC-1009) was developed and modeled after NC-140. Horticulturists, plant pathologists, and entomologists from 14 institutions in the United States and two in Canada established a uniform method for apple cultivar trials to determine their susceptibility to pests and adaptability to a wide range of growing conditions. This multidisciplinary team has also published results in scientific journals and presented cultivar information at meetings intended for commercial apple growers. Project details are available on the NIMSS website (NIMSS, $2012 b$ ) and on the project website (NE-183 Regional Research Project, 2006). Results of other studies comparing the relative susceptibility of new cultivars to pathogens such as the rust diseases, powdery mildew, and apple scab have also been published in scientific journals (Biggs and Miller, 2005; Biggs et al., 2009a, 2009b, 2010a, 2010b).

The NC-140 and NECC-1009 research groups have generated information archived in journal articles not readily available to most stakeholders. 
There is a great need to make current and future information easily available to traditional audiences (commercial fruit growers and state extension specialists) and to under-served stakeholders, such as extension educators, and home gardeners.

For several years, NC-140 members have considered ways to make information more widely available to stakeholders beyond commercial apple growers. Both NC-140 (NC-140 Regional Research Project, 2012) and NECC-1009 (NE-183 Regional Research Project, 2006) have websites with a project summary, links to cooperators, annual meeting minutes, citations for refereed and non-refereed papers resulting from these projects, as well as descriptions of completed, current, and planned projects. Most tree fruit extension specialists have websites with information intended for commercial growers, but less information is available for other stakeholder groups. For example, NC-140 cooperators recently developed an online interactive Apple Tree Spacing Calculator, but it needs to be modified for different regions and for the home gardener (Perry et al., 2008).

We have formed an eXtension $\mathrm{CoP}$ to assemble this information in one place and make it available to a wide range of stakeholders in a practical, easy-to-use format. In addition, housing this research-based information at eXtension will help bring other experts to the CoP and expand the breadth of knowledge available to the CoI. Initially, the CoP will focus on information pertaining to the eastern United States (defined as longitude $<95^{\circ} \mathrm{W}$ ) since performance of rootstocks and cultivars are quite different in the western United States. To maximize efficiency at launching the $\mathrm{CoP}$ on eXtension, cooperators agreed to start with this region and limit content to rootstocks and cultivars. We expect that once rootstocks and cultivars are addressed, other apple production information will be worked into the CoP.

One might wonder why we need a $\mathrm{CoP}$ when we have search engines such as Google. Arguably, presently most Internet searches start with Google. We suspect that many orchardists looking for apple rootstock and cultivar information use Google. While Google connects users to a wide array of content-providers, the sheer number of results confounds many users who use "apple" as a search term [this problem is compounded by the existence of the computer company Apple ${ }^{\circledR}$ (Cupertino, CA)]. It is physically impossible to explore all of the search results returned by Google on apple cultivars and rootstocks. By having our CoP housed at eXtension our material will be search-engine optimized, increasing the chance our research-based information rises toward the top of a search.

The eApples CoP has begun to systematize regional apple rootstock and cultivar descriptions and recommendations and, as a team, have begun discussions on types of educational products to create interest and expand the knowledge of our CoI. Several commercial apple growers and nurserymen have agreed to serve as an advisory group. As products are developed, the advisory committee will evaluate the content and provide suggestions for improvement.

Our $\mathrm{CoI}$ is diverse, ranging from highly proficient and educated professional apple growers to backyard enthusiasts. Broadly defined, our CoI will include anyone interested in apple production, including commercial apple producers, county extension educators, nursery professionals, Extension Master Gardeners, home gardeners, and consumers. Apple rootstock and cultivar information must be tailored to their needs. We need to understand and address our CoI adequately and produce content suitable for all audiences. We have begun to survey members of our CoI to provide input concerning the types of the educational materials that are desired and the most appropriate media for information delivery.

While the apple-producing CoI members are our initial target audience, these resources will not be restricted to them alone. The advantage of eXtension is that this information will be available and potentially valuable to everyone, including consumers who are interested in which apples are recommended for their local area, who want to understand how apples are grown and why certain apples may or may not be available in certain areas or at particular times of the year. In time, once the initial cultivar and rootstock content is developed, the $\mathrm{CoP}$ will be able to address more specific consumer needs such as choosing the right apple for a particular use, understanding the nutritional benefits of apples, and so on. In the meantime, all visitors to eXtension will have the "Ask an Expert" tool to connect with CoP members, who will be available to answer questions on content not yet found on the eApples site.

A wide array of technology is now available through eXtension to connect our defined CoI with information. The website contains brief articles linking people to additional resources, frequently asked questions, and Ask an Expert tool. As our website continues to develop, we will include videos, web-conferencing, and online selfpaced units on specific topics to enhance educational opportunities. A Facebook (Menlo Park, CA) page has been created as the project continues to communicate and draw individuals into the $\mathrm{CoP}$ and engage our CoI.

This group of researchers and extension personnel are excited to bring the resources we have developed to a broader audience. Working cooperatively with USDA-NIFA, eXtension, state experiment stations, and extension services will allow more research-based information to truly be extended to stakeholders.

\section{Literature cited}

Autio, W., T. Robinson, W. Cowgill, C. Hampson, M. Kushad, J. Masabni, P. Quezada, R. Perry, and C. Rom. 2008. Performance of 'Gala' apple trees on supporter 4, P.14, and different strains of B.9, M.9 and M.26 rootstocks: A five-year report on the $2002 \mathrm{NC}-140$ apple rootstock trial. J. Amer. Pomol. Soc. 62:119-128.

Barden, J.A. and R.P. Marini. 1998. Incidence of diseases on fruit of nine apple genotypes as influenced by six fungicide treatments. Fruit Var. J. 52:128-136.

Biggs, A.R. and S.S. Miller. 2005. Relative susceptibility of NE-183 apple cultivars to fruit rot pathogens in West Virginia. J. Amer. Pomol. Soc. 59:72-77.

Biggs, A.R., D.A. Rosenberger, K.S. Yoder, R.K. Kiyomoto, D.R. Cooley, and T.B. Sutton. 2009a. Relative susceptibility of selected apple cultivars to cedar apple rust and quince rust. Plant Health Prog. Online doi: 10.1094/PHP-20091014-01-RS.

Biggs, A.R., K.S. Yoder, and D.A. Rosenberger. 2009b. Relative susceptibility of selected apple cultivars to powdery 
mildew caused by Podosphaera lencotricha. Plant Health Prog. Online. doi: 10.1094/ PHP-2009-1119-01-RS.

Biggs, A.R., G. Sundin, D.A. Rosenberger, K.S. Yoder, and T.B. Sutton. 2010a. Relative susceptibility of selected apple cultivars and selections to apple scab caused by Venturia inaequalis. Plant Health Prog. Online. doi: 10.1094/PHP-2010-040801-RS.

Biggs, A.R., D.R. Cooley, D.A. Rosenberger, and K.S. Yoder. 2010b. Relative susceptibility of selected apple cultivars to sooty blotch and fly speck. Plant Health Prog. Online. doi: 10.1094/PHP-2010-072601-RS.

Crassweller, R. 2008. Pennsylvania tree fruit production guide. 27 Jan. 2012. <http://agsci.psu.edu/tfpg/partl/ AGRS045-01-04.pdf/view>.

Cummins, J.N. and H.S. Aldwinckle. 1974. Breeding apple rootstocks. HortScience 9:367-372.
eXtension. 2012. eXtension. 27 Jan. 2012. <http://www.extension.org/>.

Magness, J.R. 1937. Progress in apple improvement, p. 575-614. In: Yearbook of agriculture. U.S. Dept. Agr., Washington, DC.

Marini, R. 1996. 1995 Apple variety evaluations. 27 Jan. 2012. <http://pubs. ext.vt.edu/422/422-760/422-760.html $>$.

Miller, D.D. and S.C. Myers. 2006. Annual NC-140 report. 27 Jan. 2012. <http://www. reeis.usda.gov/web/crisprojectpages/ 73736.html>.

National Information Management and Support System. 2012a. NC140: Improving economic and environmental sustainability in tree-fruit production through changes in rootstock use. 27 Jan. 2012 <http://nimss.umd.edu/homepages/ home.cfm?trackID=8896>.

National Information Management and Support System. 2012b. NECC1009:
Multidisciplinary evaluation of tree fruit cultivars. 27 Jan. 2012. <http:/ /www.nimss. umd.edu/homepages/saes.cfm?trackID= 7336>.

NC-140 Regional Research Project. 2012. NC-140 Regional rootstock research project. 27 Jan. 2012. <http://www. ncl40.org/>.

NE-183 Regional Research Project. 2006. NE-183 Apple cultivar evaluation project. 27 Jan. 2012. <http://www.nel83. org $>$.

Perry, R., J. Hull, and J.M. Clements. 2008. Apple scion/rootstock selection and planning for Michigan. 27 Jan. 2012. <http://www.umass.edu/fruitadvisor/ clements/appletreespacing.htm>.

U.S. Apple Association. 2012. Apple guide. 27 Jan. 2012. <http://www.usapple. org/consumers/all-about-apples/applevarieties-and-apple-products/varieties $>$. 